\title{
Using Flipgrid to develop social learning
}

John Stoszkowski

University of Central Lancashire

\begin{abstract}
Flipgrid is an online video discussion platform designed to empower learners and facilitate social interaction between students. This paper reviews the use of Flipgrid to develop social learning with a cohort of undergraduate students at the University of Central Lancashire. Strengths and weaknesses of the Flipgrid platform are outlined, as well as potential barriers to its use, and future plans for incorporating it in teaching and learning.
\end{abstract}

Keywords: Collaborative learning; Online learning; Education Technology.

\section{Introduction}

Flipgrid (www.flipgrid.com), an online video discussion platform, is designed to empower learners and facilitate collaboration and social learning between students. Microsoft acquired the platform in June 2018, making it freely available to educators worldwide as part of Office 365 for Education. The tutor creates a 'grid' and then invites students to upload short video responses to 'topics' (i.e. questions and prompts) via a custom link. To upload responses to a topic, as well as replies to each other's responses, students use a simple video recorder in the Flipgrid app (Android and iOS) or do so via any web browser. The user interface is intuitive and functions like many other video-based social media platforms (e.g. YouTube, Instagram and Snapchat). Students can pause while recording, with unlimited retakes possible until they are ready to upload their video. 'Grids', which essentially become collections of topics, are managed through an easy-to-navigate 'teacher dashboard'. When students 'follow' their grid, they receive an email notification whenever new content is uploaded. Video length can be limited from thirty seconds to five minutes, which encourages more focused, less ambiguous responses, as students must carefully consider how they communicate their ideas. The ability to pause and re-record videos also helps students to practise communication of their ideas before posting.

\section{How Flipgrid was used in practice}

Thirty final-year undergraduate sports coaching students, who were undertaking a community-based coaching placement, used Flipgrid during one semester to support monthly face-to-face workshops. Each workshop focused on a contemporary coaching theme, with the intervening four weeks of Flipgrid discussion based upon that theme. Three groups (or 'grids') were set up, with ten students in each group. Students took turns at posting video responses to the theme, with discussion emerging via replies to that initial response and each other's replies. At periodic intervals, students were given individual formative feedback on the clarity and content of their videos via the inbuilt feedback mechanism that Flipgrid offers. 


\section{Strengths of Flipgrid}

Access. Students do not need to create an account or 'sign-up'; they simply need the web link for their grid, which is free to access. This helps reduce any potential 'overload' of platforms in their existing digital ecosystem (Stoszkowski, McCarthy and Fonseca, 2017).

Convenience. As the discussion is asynchronous and not time- or place-dependent, it benefits 'commuter students' who live off-campus and are more likely to experience challenges in relation to their engagement beyond the classroom (Thomas and Jones, 2017). Similarly, students who spend more time in paid employment - and who typically report lower gains in learning (Neves and Hillman, 2017) - appreciate the flexibility Flipgrid offers.

Participation. Discussion is evenly distributed across the cohort. Those students who might sit back or 'free-ride' (Hall and Buzwell, 2013) in class-based discussions are more involved, whilst those who might otherwise dominate discussion are less likely to do so.

Appeal. Students appear to prefer watching each other speak on video to reading written material, which they perceive to be time-consuming and 'boring'. Students with lessdeveloped writing and reading skills also appear to prefer video-based interaction.

Formative feedback. The ability to provide - easily - regular written and/or video-based tutor feedback on videos, with the option to create custom rubrics, is in keeping with an ethos of helping students take control of their own learning (Nicol and Macfarlane-Dick, 2006). Feedback is emailed directly to the students individually and only they can see it.

Tracking. The number of views on each video, as well as total engagement time across the group, is tracked automatically. This makes it easy to monitor individual and group participation levels. Data can also be exported to Excel, which is useful if participation is to be assessed or added to other grading systems.

Compatibility. Custom integration means Flipgrid can be embedded into a range of other platforms in the students' learning ecosystem (e.g. Blackboard, Google Classroom and Microsoft Teams). YouTube/Vimeo videos, as well as files and documents hosted on other platforms (e.g. Dropbox, GoogleDocs, OneNote), can also be embedded in discussion starters.

\section{Weaknesses and potential barriers to be overcome}

Competitiveness. As is common on many social media platforms, videos can be 'liked' or 'hearted' to show agreement or approval. This can lead to competitiveness, with the confidence of some students potentially dented if a video receives fewer views or likes than others. (This feature can be deactivated if the tutor so desires.)

Equipment. To access and use the platform, students must have a suitable digital device (i.e. with camera and microphone) and a good internet connection. Students who have older or 'lower specification' phones or tablets with a sound and picture quality inferior to that of recent high-spec. models may therefore experience problems. 
Impression management. Initially, many students were concerned about gaining peer approval and 'saying the right thing' as opposed to posting genuine views and opinions. Some students prepared a script from which to read, which detracted from the authenticity of some videos and led to the appearance of some discussions as a little insincere. Over time, the tendency to do this lessened, the sharing of 'best practice' examples being particularly helpful in countering it.

Confidence. A few students were uncomfortable about being 'on screen', with some voicing concerns that their appearance would be 'judged' by their peers. Consideration should therefore be given to the suitability of the platform for introverts, although research has suggested that introverted students prefer communicating via social media to doing so in person (Voorn and Kommers, 2013).

\section{Conclusion and plans for future use}

Flipgrid is a very useful tool to facilitate social learning and help students develop video content creation skills for the digital era. It is simple and intuitive to use, and students appreciate its convenience and familiar user interface. For example, Flipgrid is similar to recording a YouTube reaction video in response to a particular subject or item of news, or to recording and sending a video note in Snapchat. Moving forward, it is intended that Flipgrid will be used with a bigger cohort of students on a year-long Level 6 module which requires them to evidence continuous self-reflection as they develop their coaching practice. Flipgrid will complement the individual blogs the students currently maintain on the module by encouraging more direct peer interaction and collaborative discussion on the common issues they are facing.

\section{Reference list}

Hall, D. and Buzwell, S. (2013) 'The problem of free-riding in group projects: Looking beyond social loafing as reason for non-contribution.' Active Learning in Higher Education, 14(1), 3749. Available at: http://journals.sagepub.com/doi/full/10.1177/1469787412467123 (Accessed: 31 January 2018).

Neves, J. and Hillman, N. (2017) 2017 Student Academic Experience Survey. York: Higher Education Academy. Available at: https://www.hepi.ac.uk/wp-content/uploads/2017/06/2017Student-Academic-Experience-Survey-Final-Report.pdf (Accessed: 31 January 2018).

Nicol, D.J. and Macfarlane-Dick, D. (2007) 'Formative assessment and self-regulated learning: A model and seven principles of good feedback practice.' Studies in Higher Education, 31(2), 199-218. Available at: https://www.tandfonline.com/doi/abs/10.1080/03075070600572090 (Accessed: 31 January 2018).

Stoszkowski, J., McCarthy, L. and Fonseca, J. (2017) 'Online peer mentoring and collaborative reflection: A cross-institutional project in sports coaching.' Journal of Perspectives in Applied Academic Practice, 5(3), 118-121. Available at: https://ipaap.napier.ac.uk/index.php/JPAAP/article/view/289 (Accessed: 31 January 2018). 
Thomas, L. and Jones, R. (2017) Student engagement in the context of commuter students. London: The Student Engagement Partnership. Available at: www.tsep.org.uk/resources (Accessed: 31 January 2018).

Voorn, R.J.J. and Kommers, P.A.M. (2013) 'Social media and higher education: Introversion and collaborative learning from the student's perspective.' International Journal of Social Media and Interactive Learning Environments, 1(1), 59-73. Available at: https://www.inderscienceonline.com/doi/abs/10.1504/IJSMILE.2013.051650 (Accessed: 31 January 2018). 